\title{
Chondroid Syringoma of Dorsum of the Nose
}

\author{
Netra Aniruddha Pathak, ${ }^{1}$ Vidya Vasant Rokade, ${ }^{1}$ Kiran Jayawant Shinde ${ }^{1}$
}

\section{Introduction:}

\section{ABSTRACT}

Chondroid syrigomas are rare, usually benign tumors occurring predominantly in the head and neck area. These are also known as mixed tumors of skin. Preoperative diagnosis is difficult and generally histopathology examination confirms the diagnosis. The usual presentation is that of a slowly growing mass.

Case Report:

A rare case of chondroid syringoma on dorsum of external nose in 30 year old female patient is presented.

Discussion:

Chondroid syringoma presents as slow-growing, painless, subcutaneous or intracutaneous nodule in middle-aged adult males. The tumor is often initially confused with more common dermatologic skin disorders such as sebaceous cysts, dermoid cysts, neurofibromas, dermatofibromas, basal cell carcinoma, histiocytoma and seborrheic keratosis. The treatment of choice is surgical excision with negative margins with follow-up to detect recurrences.

Kevwords:

Deafness; Infant, Newborn; Hearing Tests; Evoked Potentials, Auditory, Brain Stem; Audiometry, Evoked Response; Otoacoustic Emissions, Spontaneous

$\mathrm{C}$ hondroid syringoma, a benign mixed tumor of the skin, is an uncommon and subcutaneous tumor composed of pleomorphic components of both epithelial and mesenchymal appearance which can be mistaken for other nodular disorders of the skin. ${ }^{1,2}$ It originates in the sweat glands, usually occurring more in head and neck than in other areas. ${ }^{3,4,5}$ The incidence of chondroid syringoma is low and ranges from 0.01 to 0.098 percent of all primary skin tumors and its incidence in men is twice that of women. ${ }^{6,78}$ It is usually found as a painless subcutaneous mass and surgery is required when it causes cosmetic disfigurement. A malignant transformation is uncommon. As no characteristic clinical features are seen definitive diagnosis can be made only by doing a histopathological examination. We are presenting this case because of its rarity in females and unusual in its site of occurrence.

1 - Department of ENT, Smt Kashibai Navale Medical college, Narhe,Pune

\section{Corresponding author:}

Dr Netra Aniruddha Pathak

email: netra.pathak@gmail.com

\section{Case Report}

A 30-year-old female patient presented with a mass on her nasal dorsum growing slowly for the last 2 years. On examination, the lesion was a firm, non-tender, nonfluctuant, measuring $2.5 \mathrm{~cm}$ (width) by $2.5 \mathrm{~cm}$ (length). Overlying skin was tethered to lesion and its colour was changed (Fig. 1) She denied pain, trauma or previous surgery to the area. The remainder of the physical examination was within normal limits. Fine needle aspiration was performed narrowing the diagnosis to a chondroid syringoma. Surgical excision of the mass was performed under general anesthesia. The diagnosis of benign chondroid syringoma was made upon histopathological examination of the surgical specimen showing lace-like pattern of the tubule-alveolar structures. (Fig. 2) Negative margins were obtained on frozen section. Wide local excision of mass was done by keeping safety margin of $1.5 \mathrm{~cm}$ to prevent recurrence. The size of the defect was large enough to preclude primary skin closure. Hence the wound was closed with a paramedian forehead flap. (Figs. $3 \& 4$ ) The patient recovered uneventfully from surgery and after 6 weeks, 


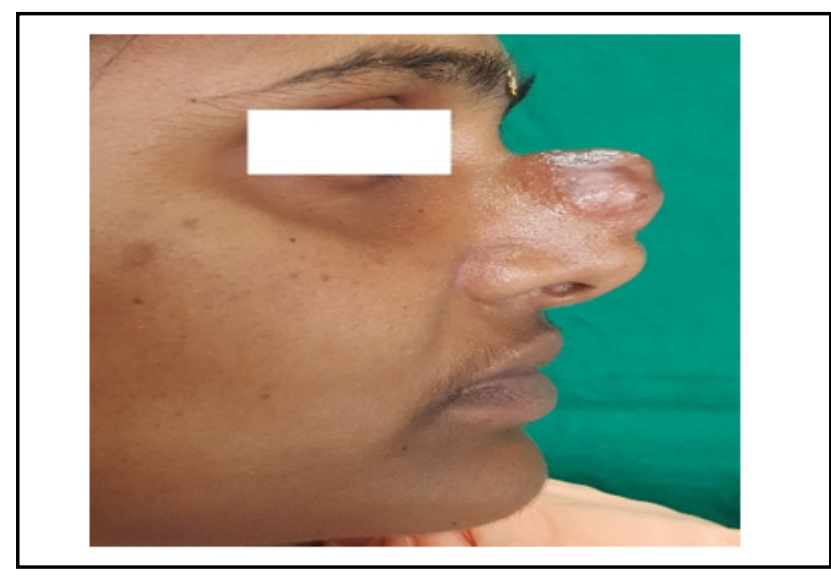

Fig.1. Mass on dorsum of the nose

the pedicle was divided and there had been no sign of recurrence on follow-up examinations.

\section{Discussion}

Chondroid syringoma presents as slow-growing, painless, subcutaneous or intracutaneous nodule in middle-aged adult males. The incidence reported in the literature ranges from 0.01 to 0.098 percent of all primary skin tumors. The tumor has been found on most parts of the body, with the majority involving the skin of the head and neck region. Most lesions are small and range between 0.5 to $3 \mathrm{~cm} .{ }^{6,7,8}$ In our study also

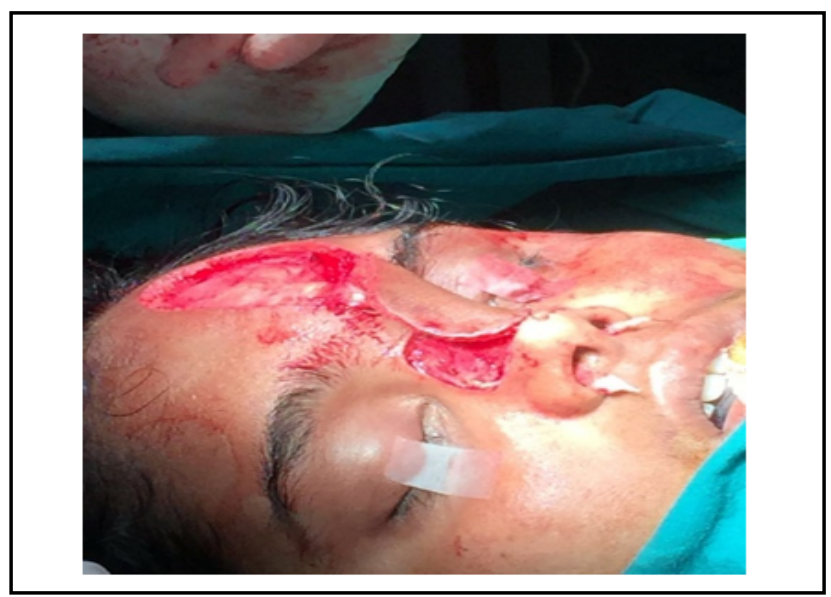

Fig.3. Paramedian forehead flap for reconstruction

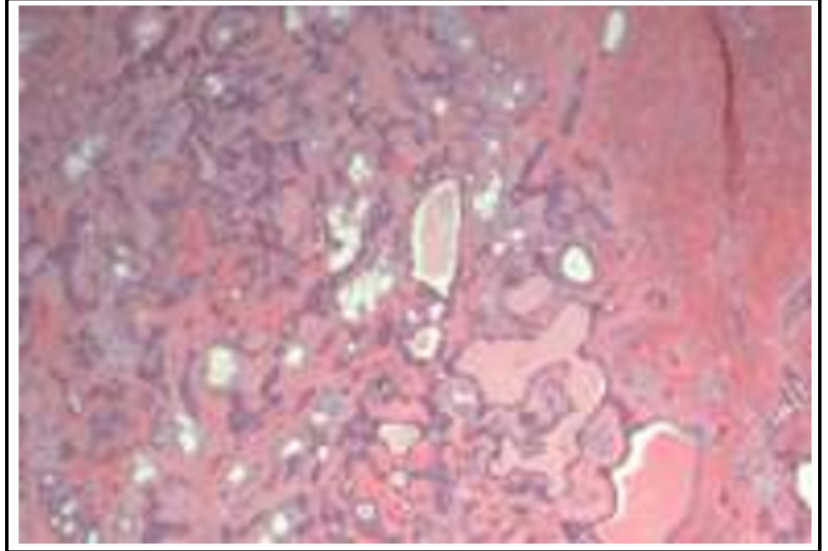

Fig.2. The lace-like pattern of the tubuloalveolar structures with the chondroid stroma is visible (H\&E,40X)

it was painless slowly growing mass over dorsum of nose. Larger tumors are extremely rare as the tumors are usually excised before causing significant cosmetic and functional impairment. Larger lesions may become ulcerated and bleed. Chondroid syringomas do not present in a distinctive manner. As a result, the tumor is often initially confused with more common dermatologic skin disorders such as sebaceous cysts, dermoid cysts, neurofibromas, dermatofibromas, basal cell carcinoma, histiocytoma and seborrheic keratosis. ${ }^{9}$ The definitive diagnosis is usually made upon histopathologic examination after surgery.

Malignant chondroid syringomas are extremely

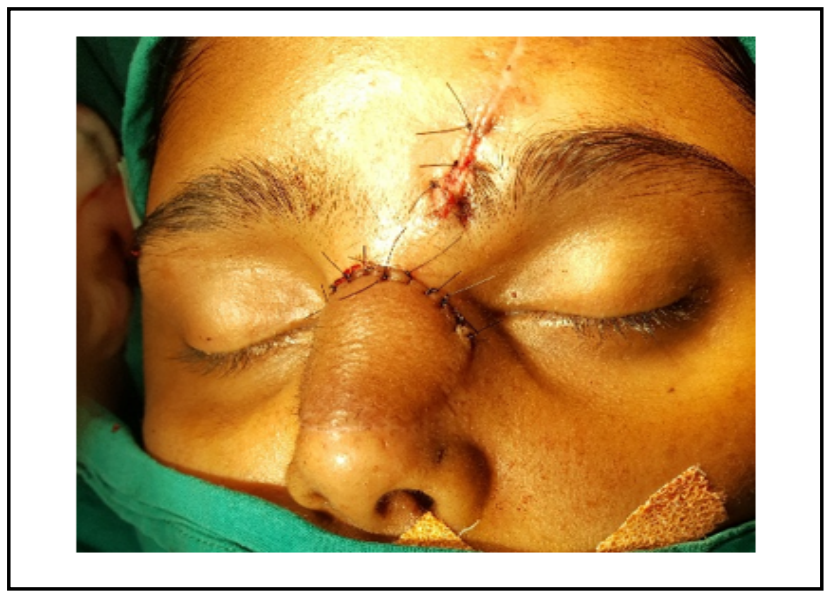

Fig.4. After excision of mass and complete closure 
rare, occurring more commonly in females and on the extremities, with a high rate of metastasis to regional lymph nodes, bones, and visceral organs. ${ }^{10}$ Atypical histological findings such as cytologic atypia, increased mitotic figures, infiltrative margins, and tumor necrosis are considered signs of malignant transformation.

Chondroid syringomas share similarities with pleomorphic adenomas which are mixed tumors that arise from the salivary glands. In contrast to pleomorphic adenomas, chondroid syringomas are thought to arise from sweat glands. Headington divided chondroid syringomas into apocrine and eccrine variants based on histological differences in the luminal morphology but there remains debate as to their exact origin. The treatment of choice is surgical excision with negative margins..$^{9,10}$ Important functional and aesthetic units should be maintained whenever possible. In our case we also did surgical excision with reconstruction for cosmesis.

The specimen should be examined closely to confirm the diagnosis and checked for malignancy. Routine follow-up is recommended as recurrence rates have been reported in 2.4 to 10 percent of cases. In most cases, recurrence occurs as a result of incomplete excision.

\section{References}

1. Hirsch P, Helwig EB. Chondroid syringoma. Mixed tumor of skin, salivary gland type. Arch Dermatol,1961;84: 835-47

2. Yavuzer R, Basterzi Y, Sari A, Bir F, Sezer C. Chondroid syringoma: a diagnosis more frequent than expected. Dermatol Surg. 2003;29(2): 179-81

3. Stout AP, Gorman JG. Mixed tumors of the skin of the salivary gland type. Cancer 1959;12(3): 537-43

4. Sungur N, Uysal A, Gumus M, Kocer U. An unusual chondroid syringoma. Dermatol Surg. 2003; 29(9): 977-9

5. Sheikh SS, Pennanen M, Montgomery E. Benign chondroid syringoma: report of a case clinically mimicking a malignant neoplasm. J Surg Oncol. 2000;73(4): 228-30

6. Harrist TJ, Aretz TH, Mihm MC, Jr., Evans GW, Rodriquez FL. Cutaneous malignant mixed tumor. Arch Dermatol. 1981;117(11): 719-24

7. Ishimura E, Iwamoto $\mathrm{H}$, Kobashi $\mathrm{Y}$, Yamabe H, Ichijima K. Malignant chondroid syringoma. Report of a case with widespread metastasis and review of pertinent literature. Cancer 1983;52(10):1966-73

8. Metzler G, Schaumburg-Lever G, Hornstein O, Rassner G. Malignant chondroid syringoma: immunohistopathology. Am J Dermatopathol. 1996;18(1): 83-9

9. Steinmetz JC, Russo BA, Ginsburg RE. Malignant chondroid syringoma with widespread metastasis. J Am Acad Dermatol. 1990;22(5 Pt 1): 845-7

10. Takahashi H, Ishiko A, Kobayashi M, Tanikawa A, Takasu H, Md MT. Malignant chondroid syringoma with bone invasion: a case report and review of the literature. Am J Dermatopathol. 2004;26(5): 403-6. 